\title{
Susceptibility of Brown Planthopper (Nilaparvata lugens Stal.) from Cipunagara and Banyuwangi Population to Neem Oil Formulation
}

\author{
Neneng Sri Widayani ${ }^{1}$, Danar Dono ${ }^{2} *$, Yusup Hidayat ${ }^{2}$ \\ ${ }^{1}$ Agronomy Magister program, Faculty of Agriculture, Universitas Padjadjaran, Jatinangor, West Java, Indonesia, 45363 \\ ${ }^{2}$ Department of Plant Pests and Diseases, Agriculture Faculty, Universitas Padjadjaran, Jatinangor, West Java, Indonesia, \\ 45363.
}

*Corresponding author: danar.dono@unpad.ac.id

\begin{abstract}
Brown Planthopper is one of the pests that cause problems in rice production. This study was conducted to know the tendency of using a kind of insecticide and to examined the susceptibility of brown planthopper from field population (Cipunagara, West Java) compared to standard population (Banyuwangi, East Java) to formulation insecticide of neem oil 50 EC. Observations were-conducted on Cipunagara farmers to find out the kind of insecticide used and the number of insecticide applications in one season. the susceptibility test to neem oil $50 \mathrm{EC}$ formulation was conducted by root dipping method. Brown planthopper was feed on treated plant for two days and then the next day the Brown Planthopper was fed on rice plant without treatment until the eighth day. Test insects used are brown planthopper instar $4^{\text {th }}$. Observations of insect mortality test for ten days with an interval of every 24-hour observation. Susceptibility values for neem oil insecticide formulations were determined based on the resistance ratio (RR) by comparing the $\mathrm{LC}_{50}$ value of the field population and standard population. Result of the observations showed that the farmers in the Padamulya village, Cipunagara district generally using synthetic insecticides to control of this pest. The active ingredient of most mentioned was imidacloprid with a lot of different applications. The result of examination of insecticide formulation of neem oil $50 \mathrm{EC}$ using the root dipping method showed that a slow death trend and the highest mortality at eight days after application. The $\mathrm{LC}_{50}$ value of neem oil 50 EC insecticide against brown planthopper in the field population (Cipunagara) was $0.36 \%$ and RR 0.98 . The result indicated that brown planthopper origin from Cipunagara was still susceptible to neem oil 50 EC insecticide formulation.

Keyword: Neem oil formulation, Susceptilbility, Resistance ratio, Brown Planthopper
\end{abstract}

\section{ABSTRAK}

\section{Kepekaan Wereng Coklat (Nilaparvata lugens Stal.) Asal Populasi Cipunagara dan Banyuwangi terhadap Formula Minyak Mimba}

Wereng coklat (Nilaparvata lugens) merupakan salah satu hama yang menyebabkan permasalahan pada produksi padi. Penelitian bertujuan untuk mengetahui kecenderungan penggunaaan suatu jenis insektisida dan untuk mengetahui kepekaan wereng coklat asal populasi lapangan (Cipunagara, Jawa Barat) yang dibandingkan dengan populasi standar peka (Banyuwangi, Jawa Timur) terhadap insektisida formulasi minyak mimba 50 EC. Observasi dilakukan terhadap para petani untuk mengetahui jenis insektisida yang digunakan dan jumlah aplikasi insektisida dalam satu musim. Uji kepekaan wereng coklat terhadap formulasi insektisida minyak mimba dilakukan dengan metode rendam akar. Wereng coklat dibiarkan makan pada tanaman yang diberi perlakuan selama dua hari, kemudian pada hari selanjutnya diberi tanaman pakan tanpa perlakuan hingga hari kesepuluh. Serangga uji yang digunakan adalah wereng coklat instar 4. Pengamatan terhadap kematian serangga uji selama sepuluh hari dengan interval pengamatan setiap 24 jam. Nilai kepekaan terhadap formula insektisida minyak mimba ditentukan berdasarkan nilai nisbah resistensi (NR) dengan membandingkan niliai $\mathrm{LC}_{50}$ dari populasi lapang dan populasi standar. Hasil observasi menunjukkan bahwa petani di Desa Padamulya Kecamatan Cipunagara umumnya menggunakan insektisida sintetik untuk pengendalian hama tersebut. Bahan aktif yang paling banyak digunakan adalah imidakloprid dengan jumlah aplikasi yang berbeda-beda. Hasil pengujian formulasi minyak mimba menggunakan metode rendam akar memperlihatkan kecenderungan kematian yang lambat dan baru menunjukkan hasil kematian yang tinggi pada delapan hari setelah aplikasi. Nilai $\mathrm{LC}_{50}$ formula insektisida minyak mimba 50 EC terhadap wereng coklat populasi lapang adalah $0,36 \%$ dan nilai NR 0,98. Hasil uji terhadap insektisida minyak mimba 50 EC menunjukkan bahwa wereng coklat asal poulasi Cipunagara masih peka terhadap insektisida tersebut.

Kata Kunci: Formula minyak mimba, Kerentanan, Nisbah Resistensi, Wereng Coklat

\section{PENDAHULUAN}

Wereng coklat (Nilaparvata lugens Stal. (Homoptera: Delphacidae) merupakan salah satu hama utama yang menyebabkan permasalahan cukup serius pada tanaman padi. Wereng coklat memiliki kemampuan yang baik dalam mematahkan efektivitas insektisida sehingga dapat terjadi resistensi (Baehaki, 2012). Resistensi wereng coklat terhadap insektisida umumnya terjadi terhadap insektisida sintetik dengan bahan aktif tertentu. Mustikarini \& Simanjuntak
(2014) menyebutkan bahwa loyalitas petani dalam menggunakan insektisida berkorelasi positif dengan frekuensi penggunaan insektisida. Penggunaan insektisida lebih banyak dari seharusnya disebabkan oleh petani berlebihan dalam meramalkan serangan hama dan anggapan tanamannya tidak dapat menghasilkan tanpa aplikasi insektisida (Mariyono dkk., 2001). Seiring dengan berjalannya waktu, telah diketahui berbagai efek negatif yang disebabkan oleh penggunaan insektisida sintetik. Insektisida sintetik 
menyebabkan pencemaran lingkungan, peningkatan biaya untuk pengendalian hama (Fernandes et al., 2010), mempengaruhi antropoda nontarget (Souza et al., 2012), resistensi hama dan resurgensi hama (Abrol \& Shankar, 2014). Berdasarkan paparan tersebut, diperlukan alternatif pengendalian lain yang bersifat ramah lingkungan dan mencegah terjadinya resistensi terhadap insektisida.

Insektisida minyak mimba merupakan salah satu insektisida yang ramah lingkungan. Pengelolaan hama resisten dapat juga dilakukan dengan menggunakan insektisida yang memilki cara kerja kompleks seperti minyak mimba. IRAC (2017) menyebutkan bahwa insektisida dengan mode of action yang komplek dapat mempersempit peluang terjadinya resistensi serangga. Insektisida nabati mimba (Azadirachta indica A. Juss) memiliki spektrum yang luas (Suryaningsih \& Hadisoeganda, 2007), dapat menghambat atau menunda perkembangan serangga, gangguan pada proses molting, dan gangguan pada perkembangan ovarium (Pathak \& Tiwari, 2017).

Penelitian ini bertujuan untuk mengetahui kepekaan wereng coklat dari dua populasi berbeda. Populasi pertama merupakan populasi Banyuwangi (standar peka) sedangkan populasi kedua merupakan wereng coklat dari Kecamatan Cipunagara, Jawa Barat. Kecamatan Cipunagara merupakan daerah budidaya intensif padi dan petani umumnya menggunakan insektisida sintetik sebagai cara pengendalian hama.

\section{BAHAN DAN METODE}

Serangga uji yang digunakan berasal dari dua populasi berbeda yaitu wereng coklat populasi standar peka dan populasi lapangan. Wereng coklat populasi standar peka berasal dari Balai Besar Penelitian Padi Sukamandi (BBPadi) dengan asal populasi dari Banyuwangi. Wereng coklat standar peka sudah direaring selama 35 generasi tanpa paparan insektisida. N. lugens populasi lapangan diambil dari Desa Padamulya, Kampung Babakan Bandung, Kecamatan Cipunagara, Kabupaten Subang, Jawa Barat pada bulan Juli 2018. Observasi juga dilakukan di Desa Padamulya terhadap 10 orang petani untuk mengetahui kebiasaan petani dalam menggunakan insektisida. Dari hasil wawancara diketahui jenis insektisida yang digunakan serta jumlah aplikasi yang digunakan.

Uji kepekaan wereng coklat terhadap insektisida nabati minyak mimba dilakukan dengan metode rendam akar. Tanaman padi yang digunakan untuk pemeliharaan dan pengujian $N$. lugens adalah padi varietas IR64. Pengujian dilakukan dengan jumlah serangga uji 60 wereng coklat per perlakuan. Konsentrasi insektisida yang digunakan berupa seri konsentrasi (5 konsentrasi dan kontrol). Pembuatan konsentrasi uji dilakukan dengan pengenceran. Pengencer yang digunakan adalah akuades yang telah diberi pengemulsi alkilaril poliglikol eter $400 \mathrm{mg} / \mathrm{l}$
Agristic $^{\circledR}$ ) dengan konsentrasi 0,5 ml/liter. Perlakuan kontrol hanya menggunakan pelarut akuades ditambah pengemulsi. Penentuan konsentrasi insektisida uji dilakukan dengan cara uji pendahuluan dan uji lanjutan.

Uji pendahuluan dilakukan untuk menentukan batas atas dan batas bawah konsentrasi, yaitu konsentrasi pada tingkat yang diharapkan mengakibatkan kematian serangga uji antara $0 \%<\mathrm{X}$ $<100 \%$. Dari hasil uji ini diperoleh batas bawah dan batas atas konsentrasi untuk menghitung selang konsentrasi. Selanjutnya, selang konsentrasi digunakan untuk mendapatkan seri konsentrasi berupa deret geometri yang akan digunakan pada uji lanjutan (5 konsentrasi dan kontrol).

Metode rendam akar dilakukan dengan cara tanaman uji berumur 10-12 hari setelah semai dibersihkan akarnya dari tanah yang menempel. 10 tanaman tersebut dimasukkan ke dalam steroform berlubang (diameter $5 \mathrm{~cm}$, tebal $1 \mathrm{~cm}$, diameter lubang $1 \mathrm{~cm}$ ) dan dimasukkan ke dalam tabung plastik (diameter $5 \mathrm{~cm}$, tinggi $5,5 \mathrm{~cm}$ ) yang telah berisi $25 \mathrm{ml}$ insektisida uji sesuai konsentrasi (Gambar 1). Selanjutnya, tabung ditutup dengan kurungan plastik berbentuk silinder berdiameter $5 \mathrm{~cm}$ dan tinggi $20 \mathrm{~cm}$. Kemudian sebanyak 10 wereng coklat instar 4 dimasukkan ke dalam kurungan tersebut. Dua hari setelah perlakuan, pakan dan larutan insektisida uji diganti dengan pakan tanpa perlakuan, dan pergantian pakan dilakukan setiap dua hari sekali. Pengamatan kematian dilakukan pada interval 24 jam selama 10 hari.

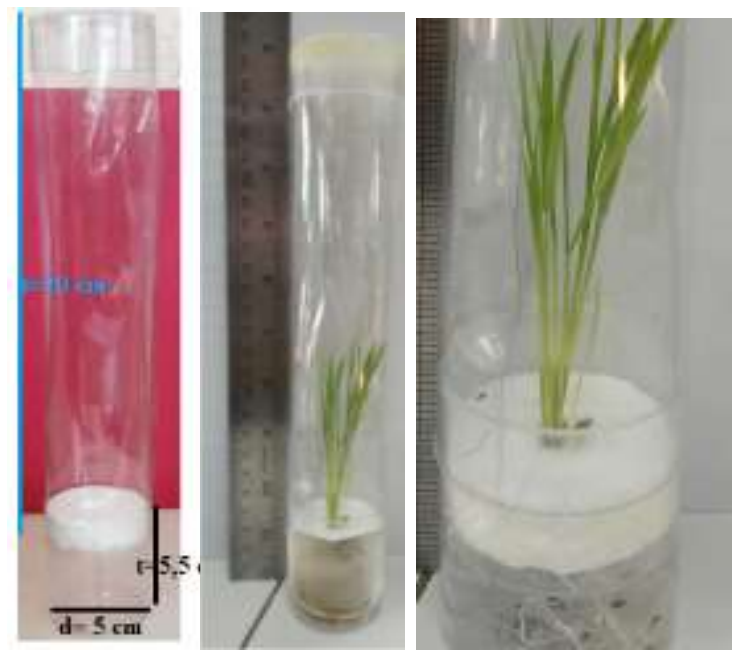

Gambar 1. Tabung dan kurungan yang digunakan untuk pengujian metode rendam akar

Data selanjutnya dianalisis menggunakan aplikasi Polo Plus Versi 1.0 untuk mendapatkan nilai $\mathrm{LC}_{50}$ dan $\mathrm{LC}_{95}$. Pada uji kepekaan ini, tolak ukur kepekaan serangga terhadap insektisida nabati digunakan nisbah resistensi (NR). Jika NR $<1$ berarti serangga yang berasal dari populasi lapangan 
(Cipunagara) peka terhadap insektisida nabati (Dono dkk., 2010).

Nisbah Resistensi (NR)=

$$
\frac{\mathrm{LC}_{50} \text { serangga populasi lapangan }}{\mathrm{LC}_{50} \text { serangga populasi standar }}
$$

\section{HASIL DAN PEMBAHASAN}

Hasil observasi yang dilakukan di Desa Padamulya, Kampung Babakan Bandung Kecamatan Cipunagara, Kabupaten Subang menunjukkan bahwa petani umumnya menaman padi sebagai komoditas utama. Petani menyatakan bahwa wereng coklat merupakan salah satu hama utama yang menyerang tanaman padi. Pengendalian yang dilakukan umumnya adalah insektisida sintetik dengan jenis dan interval aplikasi yang berbeda.

Hasil tabulasi dari wawancara terhadap 10 orang petani memperlihatkan bahwa sebanyak 32\% petani menggunakan bahan aktif imidakloprid (neonikotinoid), 28\% pimetrozil (pyridine azomethine), dan sisanya menggunakan insektisida bahan aktif fenobukarb dan karbofuran (karbamat), abamektin (avermectin), nitenpiram (neonikotinoid), serta bufropezin (bufrofezil) (Gambar 2). Jumlah aplikasi insektisida per musim tanam juga bervariasi. Sebanyak $40 \%$ petani mengaplikasikan 3-5 kali, 30\% melakukan aplikasi 1-2 kali, dan sisanya menggunakan insektisida > 5 kali (Gambar 3).

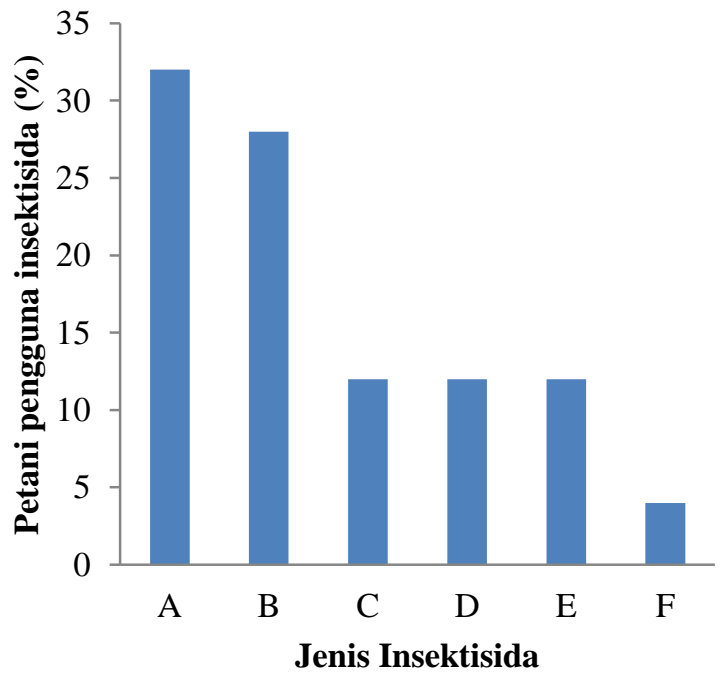

Gambar 2. Jenis bahan aktif yang digunakan oleh petani

Keterangan :

Jumlah petani yang diwawancara adalah 10 orang

A. Imidakloprid (neonikotinoid)

B. Pimetrozil (pyridine azomethine)

C. Fenobukarb dan karbofuran (karbamat)

D. Abamektin (avermectin)

E. Nitenpiram (neonikotinoid)

F. Bufropezin (bufrofezil)
Banyaknya jenis insektisida yang digunakan petani menunjukkan bahwa ketergantungan petani terhadap insektisida sangatlah besar. Pada penelitin ini diuji insektisida nabati minyak mimba sebagai alternatif pilihan insektisida yang dapat digunakan petani.

Hasil penelitian menunjukkan bahwa konsentrasi insektisida mimba yang dibutuhkan untuk menyebabkan kematian $0 \%<x<100 \%$ wereng coklat tidak berbeda antara populasi standar dari Banyuwangi dan populasi lapangan dari Cipunagara. Pada Gambar 4 dan 5 dapat dilihat bahwa mimba memiliki kerja lambat untuk mengakibatkan kematian pada wereng coklat di kedua populasi. Kematianakibat perlakuan insektisida mimba konstan pada hari ke delapan setelah aplikasi.

Uji menggunakan metode rendam akar memberikan nilai $\mathrm{LC}_{50}$ pada wereng coklat populasi standar Banyuwangi dan populasi lapangan Cipunagara berturut-turut $0,37 \%$ dan $0,36 \%$. Adapun hasil perhitungan nisbah resistensi menunjukkan bahwa $N$. lugens populasi Cipunagara masih rentan pada insektisida nabati mimba dengan nisbah resistensi < 1 (Tabel 1). Mordue \& Nisbet (2000) menyebutkan bahwa mimba memiliki peran dalam manfaatnya untuk digunakan dalam managemen resistensi. Perlakuan mimba juga telah ditunjukkan dapat mengurangi tingkat enzim detoksifikasi sehingga dapat membuat insektisida lebih efektif pada serangga resisten (Lowery \& Smirle., 2000).

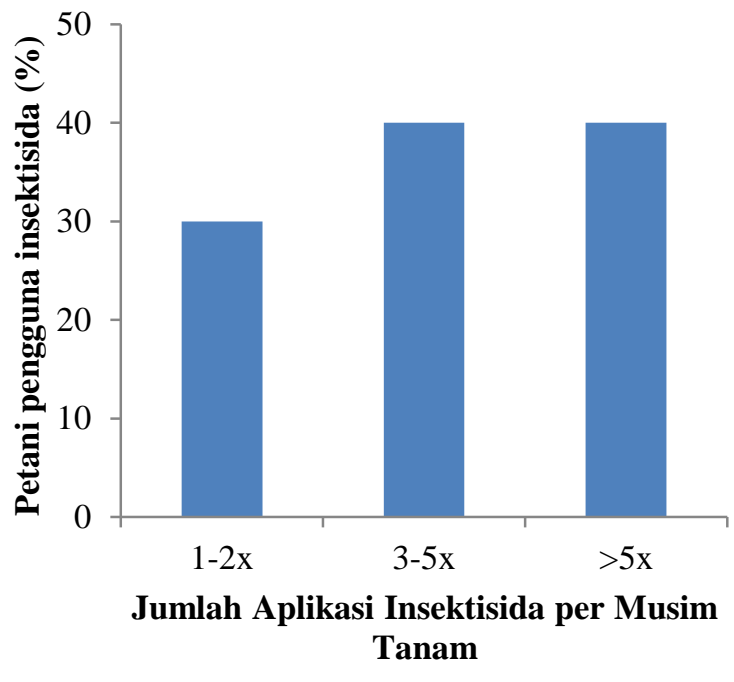

Gambar 3. Jumlah aplikasi yang dilakukan petani di Cipunagara per musim tanam 


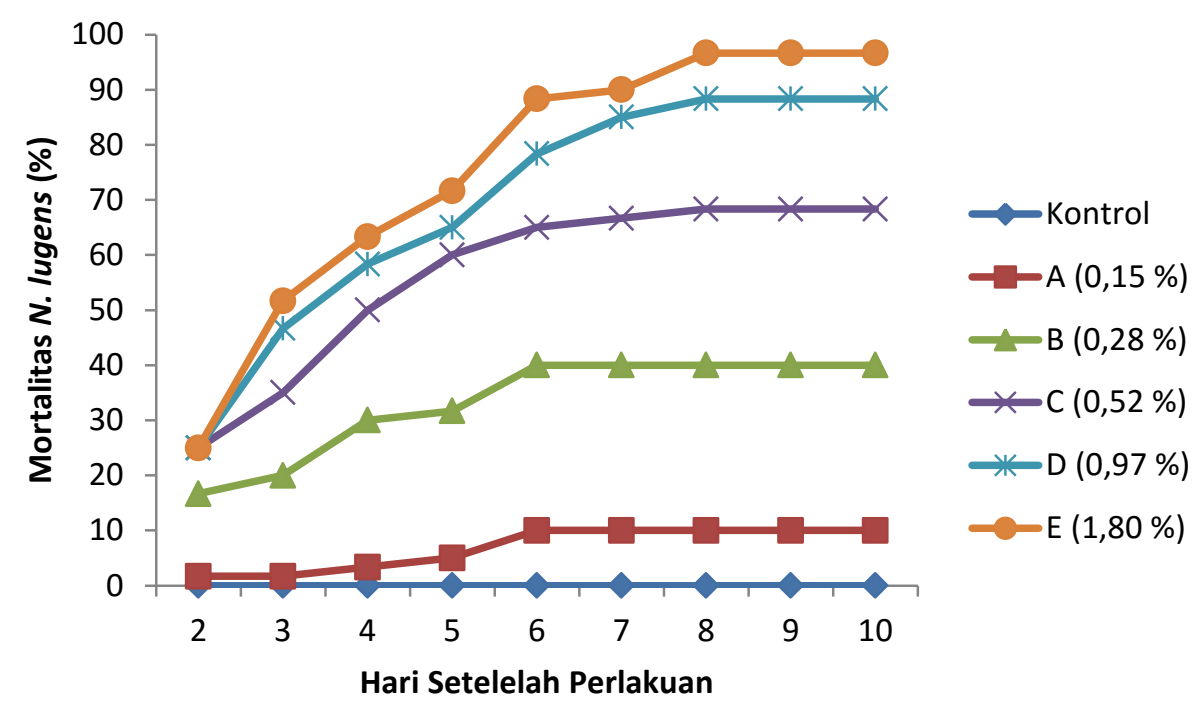

Gambar 4. Mortalitas wereng coklat populasi asal Banyuwangi (standar)

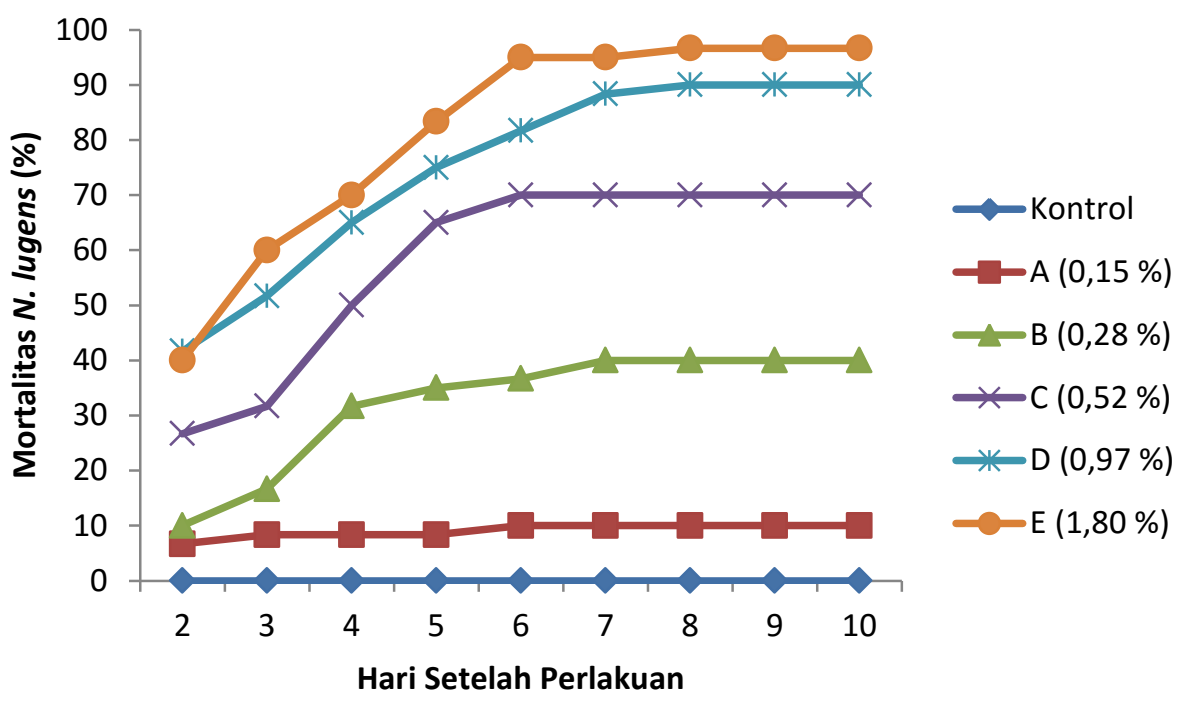

Gambar 5. Mortalitas wereng coklat populasi asal Cipunagara (lapangan)

Tabel 1. Kepekaan wereng coklat asal populasi Cipunagara (lapangan) dan Banyuwangi (standar) terhadap insektisida nabati mimba*

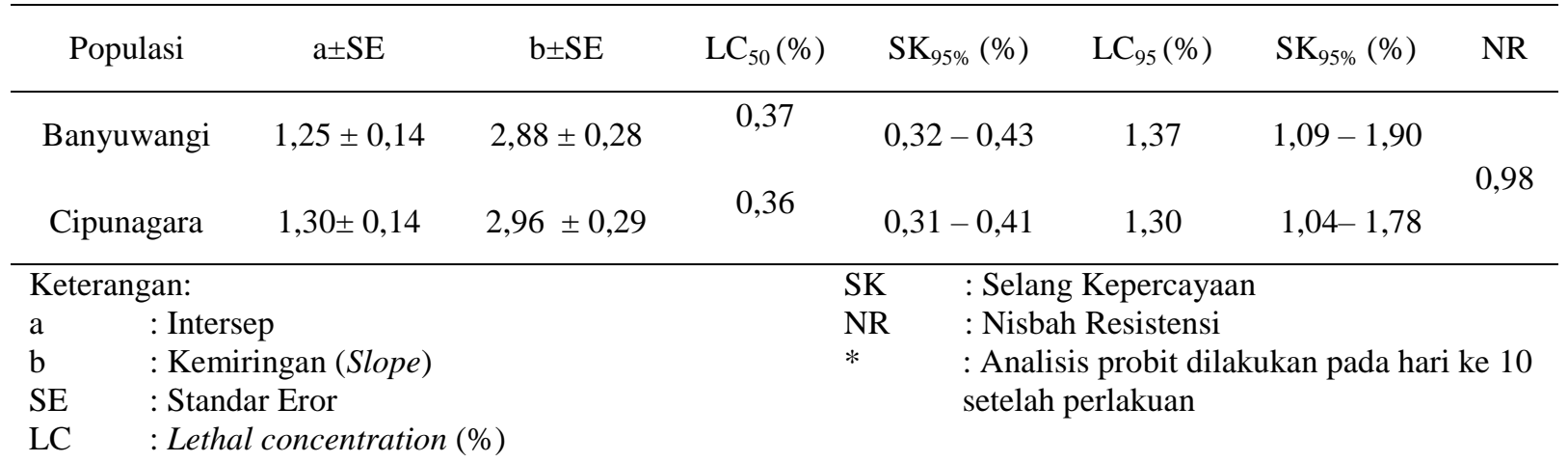

Mimba memiliki cara kerja berbeda dengan insektisida yang biasa digunakan petani seperti yang dipaparkan pada Gambar 2. Mimba sebagai insektisida nabati juga memiliki keunggulan seperti mudah terurai dan ramah lingkungan. Efek primer dari kandungan azadirachtin pada mimba berupa antifeedant dengan stimulasi deterren spesifik berupa reseptor kimia (chemoreceptor) pada bagian mulut 
(mouthpart) yang bekerja bersama-sama dengan reseptor kimia lainnya yang mengganggu persepsi rangsangan untuk makan (phagostimulant) (Mordue (Luntz) et al., 1998). Kandungan azadirachtin dapat mengganggu sistem saraf pusat Drosophila melalui penghambatan rangsangan transmisi koligenik dan menghalangi saluran kalsium (Qiao et al., 2014).

Pada uji ini digunakan metode rendam akar, sehingga diharapkan bahan aktif dari minyak mimba dapat terserap oleh tanaman padi dan dapat mematikan serangga uji. Mimba dan derivatednya bekerja sebagai insektisida sistemik, yang terabsopsi ke dalam tanaman akan terbawa ke jaringan tanaman hingga akhirnya dicerna oleh serangga ketika mereka makan (Javed et al., 2007; Senthil-Nathan et al., 2007; Weathersbee \& McKensie, 2005). Komponen fenol dari akar mimba dapat diserap oleh akar tomat yang diberi perlakukan mimba (Alam et al., 1980). Aplikasi azadirachtin dengan aplikasi pada akar atau injeksi pada batang lebih menguntungkan dalam efisiensi dan persisten serta menyebabkan perkembangan $M$. persicae terhambat dan menurunkan jumlah keturunannya (Pavela et al., 2013; Birgucu et al., 2018).

Penelitin ini menggunakan wereng coklat standar peka (Banyuwangi) sebagai pembanding kerentanan wereng coklat dari populasi lapangan (Cipunagara). Hasil uji menunjukkan bahwa populasi lapang masih rentan terhadap insektisida mimba jika dibandingkan dengan populasi standar peka.Hal tersebut menujukan bahwa mimba dapat menjadi

\section{DAFTAR PUSTAKA}

Abrol, D. P., \& Shankar, U. 2014. Pesticides, Food Safety and Integrated Pest Management. dalam Food Safety and Integrated Pest Management (hal. 167-199). https://doi.org/10.1007/978-94007-7796-5

Alam, M. M., Ahmad, M., \& Khan, A. M. 1980. Effect of organic amendments on the growth and chemical composition of tomato, eggplant and chilli and their susceptibility to attack by Meloidogyne incognita. Plant and Soil, 57 (23), 231-236.

https://doi.org/10.1007/BF02211683

Baehaki, S. E. 2012. Perkembangan biotipe hama wereng coklat pada tanaman padi. Iptek Tanaman Pangan, 7 (1), 8-17.

Birgucu, A. K., Ozger, S., Pohl, D., \& Karaca, I. 2018. Effects of Soil Application of Neem on Some Biological Characteristics of Myzus persicae (Sulzer) (Hemiptera: Aphididae). Journal of Agricultural Science, 24, 256-268.

Fernandes, F. L., Bacci, L., \& Fernandes, M. S. 2010. Impact and Selectivity of Insecticides to Predators and Parasitoids. Entomo Brasilis, 3 (1), 1-10.

IRAC. 2017. IRAC Mode of Action Classification Scheme. Tersedia di www.irac-online.org diakses pada Juni 2018 salah satu insektisida pilihan petani untuk menggunakan insektisida yang lebih ramah lingkungan. Observasi kepada petani ditujukan untuk mengetahui kebiasaan petani untuk mengendalikan wereng coklat yang diambil sampelnya dari lapangan dan kebiasaan petani dalam menggunakan insektisida. Petani juga memiliki kebiasaan melakukan rotasi insektisida jika insektisida yang sebelumnya digunakan tidak efektif. Maka dari penelitin ini, mimba juga dapat dijadikan salah satu pilihan insektisida untuk digunakan dalam rotasi insektisida untuk mengendalikan wereng coklat. Seperti yang diketahui bahwa rotasi insektisida untuk mencegah resistensi harus menggunakan insektisida yang memiliki cara kerja berbeda. Mimba memiliki kerja yang berbeda dengan insektisida yang biasa digunakan oleh petani.

\section{KESIMPULAN}

Wereng coklat populasi Cipunagara peka terhadap insektisida nabati mimba dengan nilai $\mathrm{LC}_{50}$ $0,36 \%$ dan nilai nisbah resistensi 0,98 .

\section{UCAPAN TERIMAKASIH}

Penelitian ini merupakan bagian dari penelitian Hibah Internal Unpad Skema Riset Kompetensi Dosen Unpad tahun 2018. Penulis juga mengucapkan terimakasih kepada Bapak Nono dan Ibu Rahmini dari BBPadi yang sudah berbaik hati memberikan wereng coklat dari populasi Banyuwangi untuk digunakan sebagai serangga uji.

Javed, N., Gowen, S. R., Inam-ul-Haq, M., Abdullah, K., \& Shahina, F. 2007. Systemic and persistent effect of neem (Azadirachta indica) formulations against root-knot nematodes, Meloidogyne javanica and their storage life. Crop Protection, 26 (7), 911-916. https://doi.org/10.1016/j.cropro.2006.08.011

Irham \& Mariyono, J. 2001. Perubahan cara pengambilan keputusan oleh petani pengendalian hama terpadu (PHT) dalam menggunakan pestisida kimia pada padi. Manusia dan Lingkungan. 8 (2), 91-97.

Lowery, D. T., \& Smirle, M. J. 2000. Toxicity of insecticides to obliquebanded leafroller, Choristoneura rosaceana, larvae and adults exposed previously to neem seed oil. Entomologia Experimentalis et Applicata, 95 (2), 201-207. https://doi.org/10.1023/A:1004088031262

Mordue, A. J., Simmonds, M. S. J., Ley, S. V., Blaney, W. M., Mordue, W., Nasiruddin, M., \& Nisbet, A. J. (1998). Actions of azadirachtin, a plant allelochemical, against insects. Pesticide Science, 54 (3), 277-284.

https://doi.org/10.1002/(SICI)1096-9063(19 98110)54:3<277::AID-PS801>3.0.CO;2-I

Mustikarini, F., Retnaningsih, Simanjuntak, M. 2014. Kepuasan dan loyalitas petani padi terhadap 
pestisida. Jurnal Ilm. Kel. \& Kons, 7 (2), 93102.

Pathak, C. S., \& Tiwari, S. K. 2017. Potential of neem seed's acetone extract on the haemoly mph and fat biochemistry of Cocyra cephalonica larvae (Lepidoptera: Pyralidae). Journal Adv. Zoologi, 38 (2), 164-177.

Pavela, R., ŽABKA, M., Kalinkin, V., Kotenev, E., Gerus, A., Shchenikova, A., \& Chermenskaya, T. 2013. Systemic Applications of Azadirachtin in the Control of Corythucha ciliata (Say, 1832) (Hemiptera, Tingidae), a pest of Palantus sp., Plant Protection Science. 49 (1), 27-33.

Qiao, J., Zou, X., Lai, D., Yan, Y., Wang, Q., Li, W. $\mathrm{Gu}$, H. 2014. Azadirachtin blocks the calcium channel and modulates the cholinergic miniature synaptic current in the central nervous system of Drosophila. Pest Management Science, 70 (7), 1041-1047. https://doi.org/10.1002/ps.3644

Senthil Nathan, S., Choi, M. Y., Paik, C. H., Seo, H. Y., Kim, J. D., \& Kang, S. M. 2007. The toxic effects of neem extract and azadirachtin on the brown planthopper, Nilaparvata lugens (Stål) (BPH) (Homoptera: Delphacidae). Chemosphere, 67 (1), 80-88. https://doi.org/10.1016/j.chemosphere.2006.09. 045

Souza, C. R., Sarmento, R. A., \& Venzon, M. (2012). Impact of insecticides on non-target arthropods in watermelon crop. SEMINA: CIENCIAS AGRARIAS, 33 (5), 1789-1802. https://doi.org/10.5433/1679-0359.2012v33n5 p1789

Suryaningsih, E., \& Hadisoeganda, A. W. . (2007). Pengendalian Hama dan Penyakit Penting Cabai dengan Pestisida Biorasional. Journal Hortikultura, 17 (3), 261-269. https://doi.org/10.1002/aelm.201400015

Weathersbee, A. A., \& McKensie, C. L. 2005. Effect of a neem biopesticide on repellency, mortality, oviposition, and development of Diaphorina citri (Homoptera: Psyllidae). Florida Entomologist, 88 (4), 401-407. https://doi.org/10.1653/0015-4040(2005)88[401 :EOANBO]2.0.CO;2 